This item was submitted to Loughborough's Research Repository by the author.

Items in Figshare are protected by copyright, with all rights reserved, unless otherwise indicated.

\title{
Does maximising ball speed in cricket fast bowling necessitate higher ground
} reaction forces?

\section{PLEASE CITE THE PUBLISHED VERSION}

http://dx.doi.org/10.1080/02640414.2015.1069375

\section{PUBLISHER}

(c) Taylor \& Francis

\section{VERSION}

AM (Accepted Manuscript)

\section{PUBLISHER STATEMENT}

This work is made available according to the conditions of the Creative Commons Attribution-NonCommercialNoDerivatives 4.0 International (CC BY-NC-ND 4.0) licence. Full details of this licence are available at: https://creativecommons.org/licenses/by-nc-nd/4.0/

\section{LICENCE}

CC BY-NC-ND 4.0

\section{REPOSITORY RECORD}

King, Mark, Peter J. Worthington, and Craig A. Ranson. 2019. "Does Maximising Ball Speed in Cricket Fast Bowling Necessitate Higher Ground Reaction Forces?”. figshare. https://hdl.handle.net/2134/20375. 


\title{
Does maximising ball speed in cricket fast bowling necessitate higher ground reaction forces?
}

\author{
${ }^{1}$ M.A. King, ${ }^{1}$ P.J. Worthington and ${ }^{2}$ C.A. Ranson \\ ${ }^{1}$ School of Sport, Exercise and Health Sciences, Loughborough University, Leicestershire, LE11 3TU, UK \\ ${ }^{2}$ Cardiff School of Sport, Cardiff Metropolitan University, Cyncoed Campus, Cardiff, CF23 6XD
}

\begin{abstract}
This study aimed to investigate whether high peak ground reaction forces and high average loading rates are necessary to bowl fast. Kinematic and kinetic bowling data were collected for 20 elite male fast bowlers. A moderate non-significant correlation was found between ball speed and peak vertical ground reaction force with faster bowlers tending to have lower peak vertical ground reaction force $(r=-0.364, P=0.114)$. Faster ball speeds were correlated with both lower average vertical and lower average horizontal loading rates $(r=-0.452, P=0.046$ and $r=-0.484, P=0.031$ respectively). A larger horizontal (braking) impulse was associated with a faster ball speed $(r=0.574, P=0.008)$ and a larger plant angle of the front leg (measured from the vertical) at front foot contact was associated with a larger horizontal impulse $(r=0.706, P=0.001)$. These findings suggest that there does not necessarily need to be a trade-off between maximum ball release speed and the forces exerted on fast bowlers (peak ground reaction forces and average loading rates). Furthermore, it appears that one of the key determinants of ball speed is the horizontal impulse generated at the ground over the period from front foot contact until ball release.
\end{abstract}

Keywords: cricket, fast bowling, ball speed, ground reaction forces

\section{INTRODUCTION}

Within many sporting activities, techniques that maximise performance cause larger forces and loading rates (Weyand et al., 2000) to be exerted on the body, potentially increasing the likelihood of injury (in the context of fast bowling, maximising performance can be considered as delivering the ball as fast as possible in the desired direction). In cricket fast bowling it has been suggested that bowlers who release the ball at faster speeds experience higher peak ground reaction forces and loading rates (Portus et al., 2004). Professional cricket is generally considered a moderate risk sport with overall injury prevalence of approximately $10 \%$, however one particular player type, fast bowlers, have injury prevalence exceeding $18 \%$, a rate comparable to contact sports such as Rugby Union and Australian Football (Orchard et al., 2010). Fast bowler lumbar stress fracture is the single diagnosis that results in the most lost playing time (Orchard et al., 2006). These injuries occur predominantly on the opposite (non-dominant) side to the bowling arm (Gregory et al., 2004; Ranson et al., 2005; Ranson et al., 2010) with the highest ground reaction forces in cricket fast bowling occurring during front foot contact (Hurrion et al., 2000). Previous researchers have suggested that large peak ground reaction forces during the early part of the front foot contact phase could be a major cause of lower back injuries in fast bowlers (Bartlett et al., 1996; Ranson et al., 2008). These high peak forces coincide with lower trunk movements (lower trunk extension, contralateral side-flexion and ipsilateral rotation) known to produce high contralateral facet joint contact forces (Burnett et al., 2008; Ranson et al., 2008). A fundamental issue to address, therefore, is whether these high peak ground reaction forces are unavoidable if a bowler is to generate high ball release speeds.

Various researchers have investigated the relationship between technique and ball release speed (Davis and Blanksby, 1976; Elliott et al., 1986; Bartlett et al., 1996; 
Glazier et al., 2000; Burden and Bartlett, 1990; Wormgoor et al., 2010), in particular, it has recently been demonstrated that ball speed is closely linked to a small number of technique factors. In a group of 20 elite fast bowlers, the faster bowlers in the group tended to have a quicker run-up, maintained a straighter knee throughout the front foot contact phase, had more upper trunk flexion between front foot contact and ball release, and delayed the onset of bowling arm circumduction. This relationship explained $74 \%$ of the variation in ball speed across the group of 20 bowlers (Worthington et al., 2013a). Lower peak forces and longer times to peak force during front foot contact in both horizontal and vertical directions have been associated with; a heel strike technique (where the heel is the first part of the foot to contact the ground), and a larger plant angle (angle between the downwards vertical and the hip to ankle line) (Worthington et al., 2013b). However, the link between ball speed and ground reaction forces is not clear, with few studies addressing this issue directly.

In a group of 42 high performance male fast bowlers, Portus et al. (2004) found the faster bowlers had higher peak horizontal ground reaction forces and higher average loading rates (peak force divided by time from front foot contact to peak force) than slower bowlers. It has been suggested that bowlers should use a 'flexorextender' technique, whereby their front knee initially flexes at front foot impact before extending prior to ball release. They suggested this may dissipate ground reaction forces during the early part of the front foot contact phase whilst maximising ball release speed (Bartlett et al., 1996). However, Worthington et al. (2013b) observed no significant difference in either peak vertical or peak horizontal ground reaction force when bowlers were classified according to Portus's front knee classification system (Portus et al., 2004). Although there has been a substantial amount of research on fast bowling biomechanics, it remains unclear whether achieving fast ball release speeds requires bowlers to be exposed to potentially injurious high ground reaction forces. The aim of this study was to investigate whether the fastest bowlers sustained the highest front foot ground reaction forces during the delivery stride of cricket fast bowling.

\section{METHODS}

Twenty elite male fast bowlers (mean \pm standard deviation: age $20.1 \pm 2.6$ years; height $1.88 \pm 0.08 \mathrm{~m}$; body mass $81.5 \pm 7.1 \mathrm{~kg}$ ) performed six maximum velocity deliveries of good length and direction, using their full-length run-up in an indoor practice facility. All bowlers were members of the England and Wales Cricket Board elite fast bowling group, being either current England bowlers or identified as likely to play for England within the next 3-5 years, and were deemed fit to bowl by their Team Physiotherapist. Kinematic data were collected using an 18 camera (M2 MCam) Vicon Motion Analysis System (OMG Plc., Oxford, UK) operating at $300 \mathrm{~Hz}$. Ground reaction forces were measured using a Kistler force plate $(1008 \mathrm{~Hz}, 900 \mathrm{x}$ $600 \mathrm{~mm}$, Type 9287B, Winterthur, Switzerland) during the front foot contact phase of the bowling action. The force plate was built into the indoor testing facility and had a layer of artificial grass $(25 \mathrm{~mm})$ on its surface. The testing procedures were explained to each participant in accordance with Loughborough University ethical guidelines and an informed consent form was signed. All participants conducted a thorough self-selected warm-up prior to commencing data collection.

Forty-seven $14 \mathrm{~mm}$ retro-reflective markers were attached to each participant, positioned over bony landmarks in accordance with a full-body marker set developed specifically for the analysis of fast bowlers' techniques (Figure 1, Worthington et al., 2013a). 


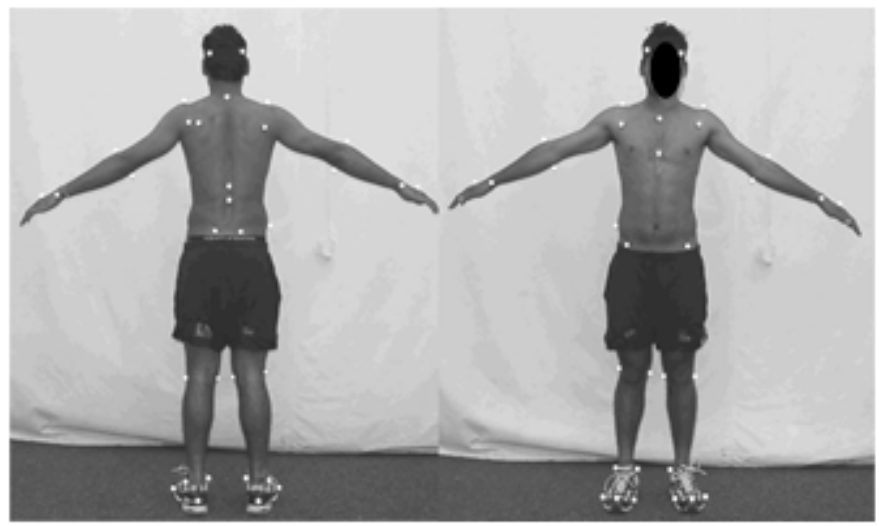

Figure 1. Marker locations.

An additional marker, in the form of a $15 \times 15 \mathrm{~mm}$ patch of 3M Scotch-Lite reflective tape, was attached to the ball. Anthropometric measurements were taken in accordance with the geometric model of Yeadon (1990). This enabled the position of the centre of mass of each bowler to be calculated throughout the bowling action.

Three trials were selected for each bowler, identified as maximal velocity deliveries with minimal marker loss. These trials were 3D reconstructed, manually labelled and analysed in Vicon's Workstation and BodyBuilder software (OMG Plc., Oxford, UK). The instants of back foot contact, and front foot contact were identified using the tracked marker positions on the feet. Ground contact was defined to be the first frame in which the motion of the markers on the foot were visually observed to change due to contact with the ground. Ball release was defined as the first frame in which the distance between the ball marker and the mid-point of the wrist markers increased by more than $20 \mathrm{~mm}$ relative to the distance in the previous image (Worthington et al., 2013a). All marker trajectories were filtered using a fourth-order low pass Butterworth filter (double pass) with a cut-off frequency of $30 \mathrm{~Hz}$ (determined using a residual analysis, Winter, 1990).

The ankle, knee, shoulder, elbow and wrist joint centres were determined using a pair of markers placed across each joint, with their mid-point corresponding to the joint centre (Ranson et al., 2008). The hip joint centres were calculated from markers placed over the left and right anterior superior iliac spine the left and right posterior superior iliac spine, and leg length (Davis et al., 1991). The upper and lower trunk motions were tracked using the four markers on the pelvis in addition to markers placed over the proximal (caudal) and distal (cephalad) ends of the sternum as well as the spinous processes of L1, T10 and C7 (Ranson et al., 2008).

Local reference frames describing a three-dimensional 18 segment full-body representation of a bowler were defined. These consisted of: head and neck; upper trunk; lower trunk; pelvis; $2 \times$ humerus; $2 \times$ radius; $2 \times$ hand; $2 \times$ femur; $2 \times$ tibia; and $2 \times$ two-segment foot. These local reference frames were defined using three markers on the segment itself, enabling segment orientations and joint angles to be calculated. The origins were located at the lower joint centre of the segment, when standing in the anatomical position. The z-axis pointed upwards along the longitudinal axis of the segment, the x-axis pointed to the participants' right (flexionextension axis of the joint) and the $y$-axis pointed forwards. Similarly, a global coordinate system was defined with the $y$-axis pointing down the wicket, the $x$-axis pointing to the right and the z-axis along the upwards vertical (Worthington et al., 2013a). Joint angles were calculated as Cardan angles, defining the rotation applied to the parent coordinate system (proximal segment) to bring it into coincidence with 
the coordinate system of the child segment (distal segment). Rotation angles were calculated using an xyz sequence - corresponding to flexion-extension, abductionadduction, and longitudinal rotation, respectively (Worthington et al., 2013a).

Six kinetic parameters were calculated for each bowling trial and their correlation with ball speed assessed. These parameters were: peak forces in the vertical and horizontal (braking) directions; average loading rates in both the vertical and horizontal directions; and the vertical and horizontal impulse between front foot contact and ball release. Peak forces, average loading rates and impulses were all normalised using the bowlers' body weight. Average loading rates were calculated as the peak force divided by the time from initial foot contact to the time of peak force (Hurrion et al., 2000).

In order to further understand the observed relationships, the kinetic variables that were significantly correlated with ball speed in this study were then correlated against key kinematic parameters that had been identified by previous studies. Four kinematic parameters that have previously been linked with ball speed (run-up speed, knee angle at ball release, upper trunk flexion (angle change from front foot contact until ball release) and shoulder angle at front foot contact; see Worthington et al., 2013a for further details), and three parameters that have been linked to peak ground reaction forces and time to peak force during front foot contact (plant angle at front foot contact, foot angle at front foot contact and knee flexion from front foot contact to ball release; Worthington et al., 2013b) were chosen for this further analysis.

The horizontal run-up speed was calculated as the mean mass centre velocity over a period of $0.060 \mathrm{~s}$ immediately prior to the instant of back foot contact. Ball release speed was calculated in a similar way, using the motion of the ball marker during a period of $0.033 \mathrm{~s}$ from the instant of ball release along with constant acceleration equations to calculate the vertical velocity of the ball. Angles describing the front knee $\left(\right.$ straight $=180^{\circ}$, flexed $<180^{\circ}$ ), upper trunk (straight $=0^{\circ}$, flexed $<0^{\circ}$ ) and shoulder (anatomical position $=0^{\circ}$, greater than $180^{\circ}$ corresponds to flexed behind the line of the trunk) corresponded to the anatomical flexion / extension angle of the joint. The foot angle at front foot contact was calculated as the angle between the global $y$-axis (horizontal line pointing down the wicket) and a line joining a projection of the ankle and MTP joint centres onto the global vertical yz plane (Worthington et al., 2013b). A positive foot angle corresponds to a 'heel strike' at front foot contact and a negative foot angle corresponds to a 'forefoot strike' at front foot contact. The two-dimensional plant angle at front foot contact was calculated as the angle between the downwards vertical and a line joining a projection of the front hip and ankle joint centres onto the global vertical (yz) plane (Worthington et al., 2013b).

All statistical analyses were performed within Statistical Package for the Social Sciences v.17 (SPSS Corporation, USA). The variation observed in each parameter (seven kinematic parameters and six kinetic parameters per bowler) was investigated using an analysis of variance to compare the between bowler variation with the between-trial variability. The relative size of the standard deviation of the betweentrial variability compared to the between bowler variability (standard deviation of the observations) ranged from $14-41 \%$ (mean 24\%) for the parameters calculated in this study, corresponding to an intra-class correlation coefficient of $0.85-0.98$ (mean 0.94). As there was good between-trial repeatability for all parameters, the three trials analysed were averaged to provide representative data for each bowler. All correlations were assessed using a two-tailed Pearson's product moment coefficient 
and were deemed to be significant for $P<0.05$. The underpinning assumptions of this statistical test were assessed and no evidence was found to indicate that they had been violated.

\section{RESULTS}

Relatively large variations in the six kinetic parameters were observed between bowlers, with the largest variation found in the average vertical loading rate where the highest value for the mean vertical loading rate was 10 times higher than the lowest value of the mean vertical loading rate (Table 1 ). Less variation was found in the kinematic variables (Table 2).

Table 1. Range, mean and standard deviation of the six kinetic parameters used in the study; peak force, average loading rate and impulse in both horizontal and vertical directions.

\begin{tabular}{lcc}
\hline \multicolumn{1}{c}{ kinetic variable } & range & mean \pm SD \\
\hline peak vertical force $(\mathrm{BW})$ & $3.99-8.63$ & $6.72 \pm 1.42$ \\
peak horizontal force $(\mathrm{BW})$ & $2.55-6.05$ & $4.47 \pm 0.75$ \\
average vertical loading rate $\left(\mathrm{BW} . \mathrm{s}^{-1}\right)$ & $85.74-892.44$ & $309.47 \pm 219.49$ \\
average horizontal loading rate $\left(\mathrm{BW} . \mathrm{s}^{-1}\right)$ & $55.16-282.12$ & $153.88 \pm 55.63$ \\
vertical impulse (BW.s) & $0.081-0.225$ & $0.174 \pm 0.031$ \\
horizontal impulse (BW.s) & $0.088-0.207$ & $0.155 \pm 0.034$ \\
\hline
\end{tabular}

Table 2. Range, mean and standard deviation of the seven kinematic parameters used in this study and ball release speed

\begin{tabular}{lll}
\hline \multicolumn{1}{c}{ kinematic parameter } & \multicolumn{1}{c}{ range } & \multicolumn{1}{c}{ mean \pm SD } \\
\hline ball release speed $\left({\left.\mathrm{m} . \mathrm{s}^{-1}\right)}^{-1}\right)$ & $32.80-39.72$ & $34.94 \pm 1.67$ \\
run-up speed $\left(\mathrm{m} \cdot \mathrm{s}^{-1}\right)$ & $4.77-6.76$ & $5.79 \pm 0.58$ \\
knee angle at BR $\left(^{\circ}\right)$ & $120-186$ & $167 \pm 19$ \\
upper trunk flexion: FFC to BR $\left(^{\circ}\right)$ & $11-51$ & $31 \pm 8$ \\
shoulder angle at FFC $\left(^{\circ}\right)$ & $288-365$ & $331 \pm 22$ \\
plant angle at FFC $\left(^{\circ}\right)$ & $27-43$ & $36 \pm 4$ \\
foot angle at FFC $\left(^{\circ}\right)$ & $-31-11$ & $-8 \pm 13$ \\
knee flexion: $\mathrm{FFC}$ to BR $\left(^{\circ}\right)$ & $0-45$ & $17 \pm 11$ \\
\hline
\end{tabular}

Note: FFC front foot contact, BR ball release

Ball speed was significantly correlated with three of the six kinetic parameters (Table 3). An increase in ball speed (relationship across the group of 20 bowlers) was significantly correlated with lower average loading rates both vertically (Figure 2a) and horizontally (Figure 2b) and a larger horizontal impulse during the period from front foot contact until ball release (Figure 2c). A moderate non-significant correlation was also observed between ball release speed and peak vertical ground reaction force, with faster bowlers tending to have lower peak vertical forces (Table 3). 

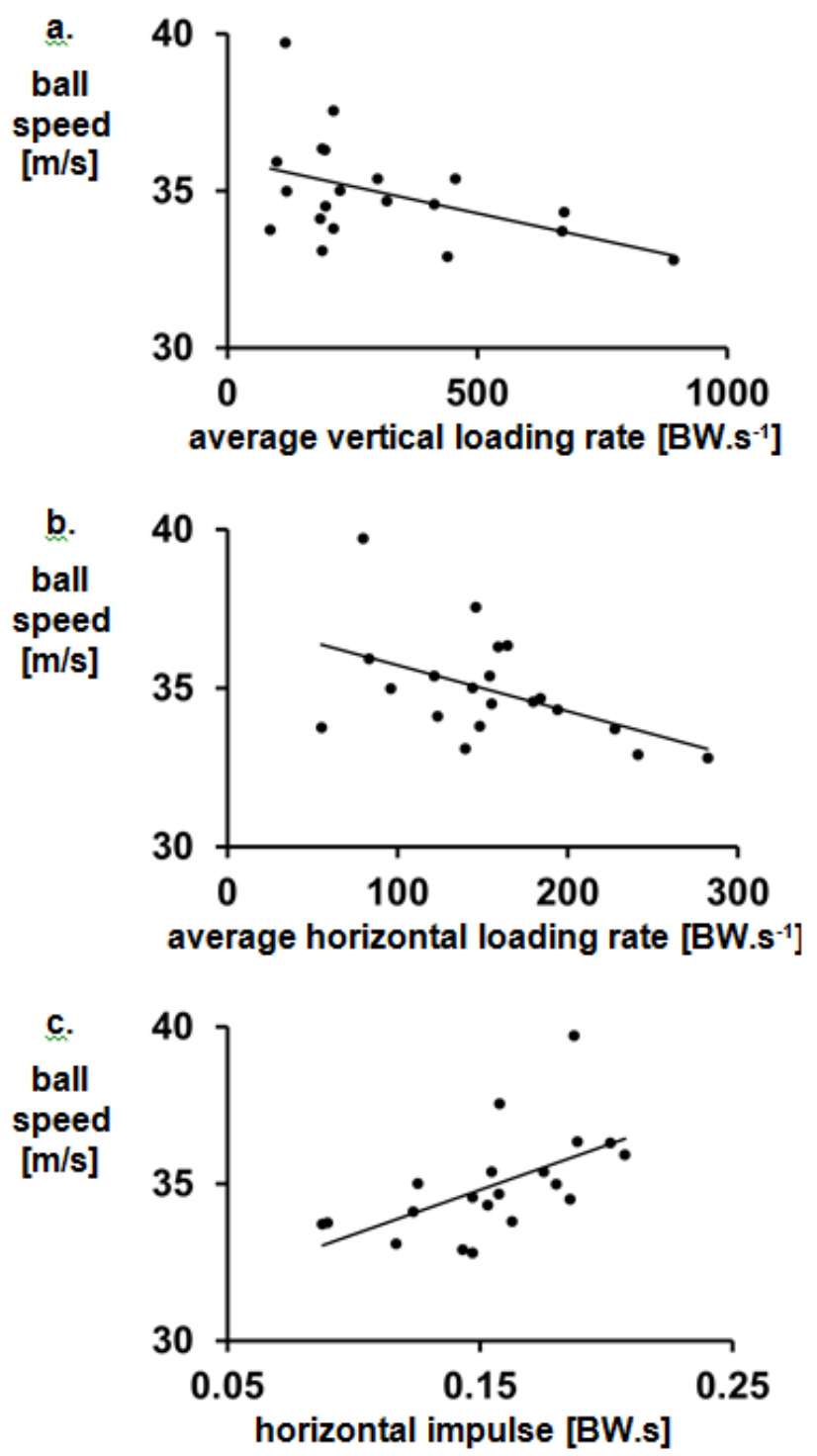

Figure 2. Relationship between ball speed and a. average vertical loading rate (front foot contact to peak force), b. average horizontal loading rate (front foot contact to peak force), and c. horizontal (braking) impulse (front foot contact to ball release). Raw data and regression line shown, see Table 3 for details.

Table 3. Correlations between ball release speed and kinetic parameters

\begin{tabular}{|c|c|c|c|c|}
\hline & \multicolumn{4}{|c|}{$\begin{array}{l}\text { 95\% confidence } \\
\text { intervals }\end{array}$} \\
\hline & r & $\begin{array}{l}\text { lower } \\
\text { bound }\end{array}$ & $\begin{array}{l}\text { upper } \\
\text { bound }\end{array}$ & $\mathrm{P}$ \\
\hline \multicolumn{5}{|l|}{ ball release speed } \\
\hline peak vertical force & -0.364 & -0.771 & 0.313 & 0.114 \\
\hline peak horizontal force & 0.078 & -0.480 & 0.692 & 0.745 \\
\hline average vertical loading rate & -0.452 & -0.666 & -0.137 & $0.046^{*}$ \\
\hline average horizontal loading rate & -0.484 & -0.793 & 0.117 & $0.031^{*}$ \\
\hline vertical impulse & 0.112 & -0.390 & 0.722 & 0.637 \\
\hline horizontal impulse & 0.574 & 0.482 & 0.686 & $0.008^{*}$ \\
\hline
\end{tabular}

* significant correlation, $\mathrm{P}<0.05$ 
The three kinetic parameters that were significantly correlated with ball speed were also each significantly correlated with at least one of the kinematic parameters calculated (Table 4). A larger horizontal impulse was positively correlated with a larger plant angle (Figure 3; front leg planted further in front of the line of the body) and moderately positively correlated with a larger shoulder angle at front foot contact (bowling arm further flexed behind the line of the trunk at front foot contact). Both average vertical loading rate and average horizontal loading rate were negatively correlated with the foot angle at front foot contact. In addition average vertical loading rate was negatively correlated with the amount of trunk flexion between front foot contact and ball release while average horizontal loading rate was moderately negatively correlated with amount of trunk flexion between front foot contact and ball release (Table 4).

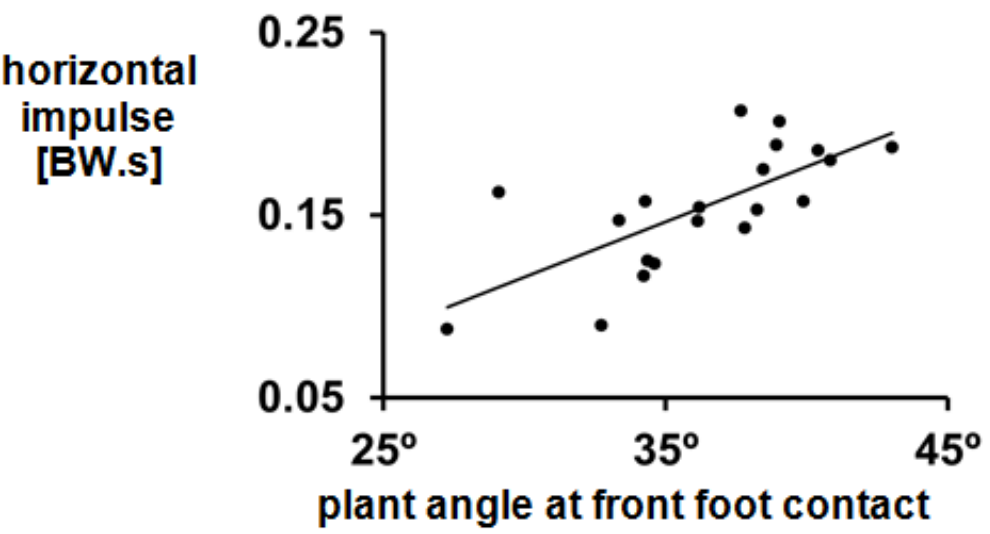

Figure 3. Relationship between plant angle at front foot contact and horizontal impulse (front foot contact to ball release). Raw data and regression line shown, see Table 4 for details. 
Table 4. Correlations between ball release speed, average vertical loading rate, average horizontal loading rate, horizontal impulse and the parameters describing the kinematics of bowling technique

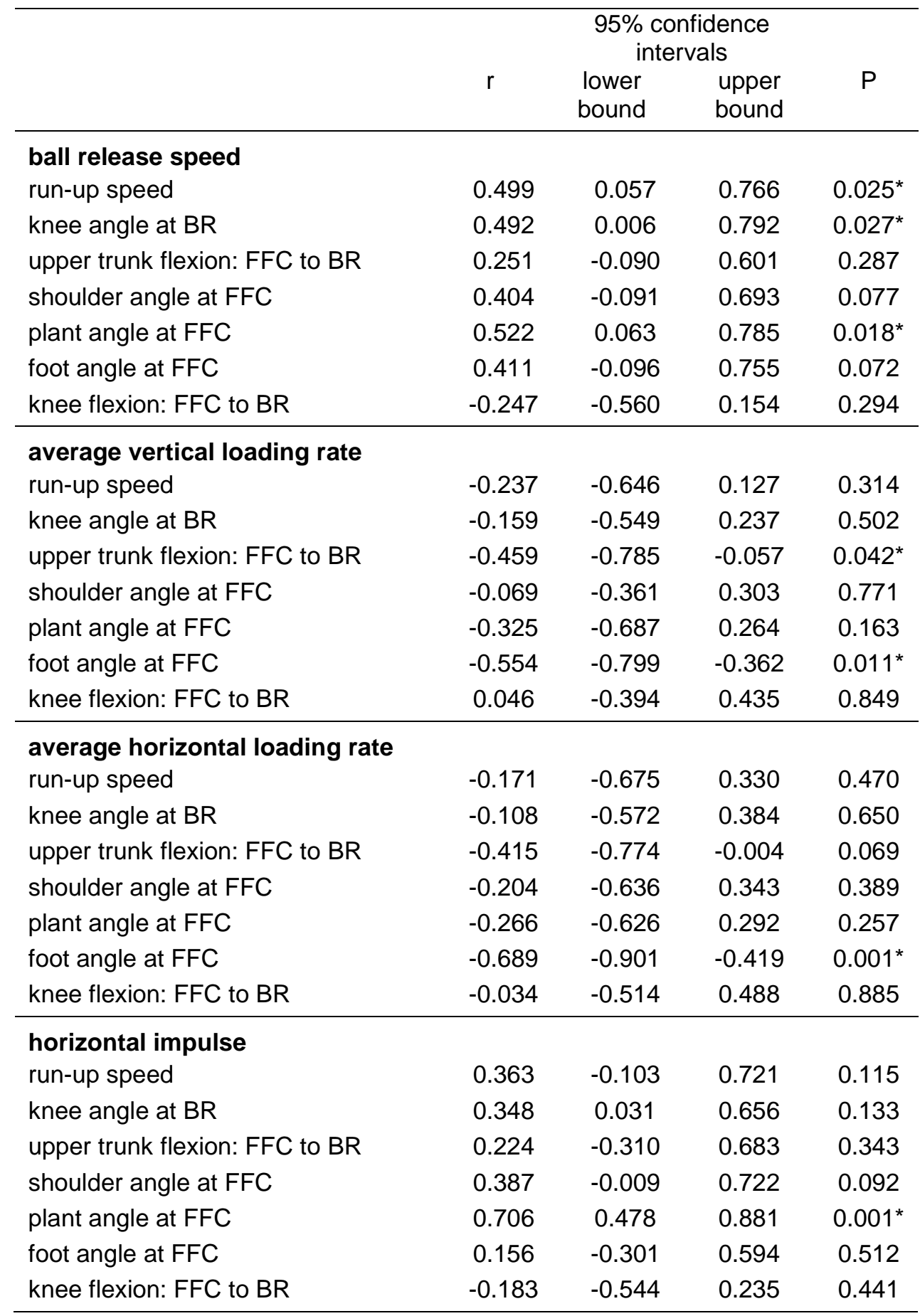

* significant correlation, $\mathrm{P}<0.05, \mathrm{FFC}$ front foot contact, BR ball release

\section{DISCUSSION}

This study has found that there is not a significant relationship between ball speed and peak ground reaction forces, therefore the faster bowlers in the group did not necessarily have the highest ground reaction forces acting on their bodies during front foot contact. Instead it would appear that having a large breaking impulse during front foot contact is key to bowling fast. An 'ideal' fast bowling technique could be thought of as one that enables the bowler to release the ball as quickly as 
possible, whilst retaining accuracy and minimising potentially injurious forces. It has previously been suggested that there is a trade-off between ball release speed and ground reaction forces, with the fastest bowlers experiencing the highest peak forces and loading rates (Portus et al., 2004). The results of the current study contradict previous findings with significant negative correlations being observed between ball release speed and loading rates both vertically and horizontally.

It has previously been suggested that bowlers should use a 'flexor-extender' technique (Bartlett et al., 1996). In this study with only small sample sizes in the different knee classifications (9 flexor-extender, 6 flexor, 3 extender and 2 constant brace; Worthington et al., 2013b) it was not possible to make definitive statements about the possible link to ball speed. Furthermore, the overall amount of knee flexion between front foot contact and ball release was not correlated with ball speed or any of the kinetic variables (Table 4), while knee angle at ball release was correlated with ball speed (Table 4). Clearly the angle changes of the front knee during front foot contact are important to fast bowling, however further work, potentially using methods such as simulation modelling is required to gain detailed understanding of the relationship between knee kinematics and ball speed. The results of the current study suggest that it is the horizontal impulse (between front foot contact and ball release) that is the key kinetic parameter determining ball speed, with larger horizontal impulse being associated with higher release speeds (Table 3 ).

Horizontal impulse had the strongest correlation with ball speed, singlehandedly explaining $33 \%$ of the variation in ball speed (Table 3, Figure 2c). Horizontal impulse was also strongly correlated with plant angle at front foot contact (50\% of the variation in impulse was explained by the value of the plant angle at front foot contact, Table 4; Figure 3). Interpreting this result in light of the previously reported association between faster ball release speeds and a quicker run-up (Worthington et al., 2013a; Table 4) gives an indication of the mechanics underlying the fast bowling action. By running up faster, a bowler has more linear momentum which corresponds to more angular momentum about the front foot. At front foot contact the foot stops moving and the body rotates about the foot. With more angular momentum the body rotates faster and this produces a faster linear velocity of the hand and ball at release. Furthermore, it is important to note that there will be an optimum run-up and inter-joint coordination pattern for a particular bowler beyond which the bowler will not be able to bowl as effectively. In the future, it is expected that theoretical models will be able to explain this relationship in more detail. The correlation between plant angle and release speed suggests that by adopting a large plant angle at front foot contact (creating a longer stride length), bowlers are able to convert more of the momentum generated during their run-up into ball speed. This mechanism is further supported by the observed link between plant angle and horizontal impulse; bowlers with a larger plant angle typically generate a larger horizontal impulse. Hence, the quickest bowlers do not necessarily require the highest horizontal (or vertical) ground reaction forces, with horizontal impulse appearing to be the most important factor.

The significant negative correlations between horizontal / vertical loading rates and ball release speed (Table 3; Figure $2 a$ and $1 b$ ) indicate that rapid increases in ground reaction forces are not necessary to bowl fast. This implies that larger horizontal (braking) impulses are produced through a longer contact time over which the ground reaction force acts to produce the impulse. Horizontal and vertical loading rates were both significantly correlated with initial foot angle suggesting that a heel strike technique reduces peak loading rates. The reasons behind the significant correlation between vertical loading rate and upper trunk flexion between front foot 
contact and ball release (Table 4) is less obvious and perhaps does not have a direct mechanical link. Theoretical studies could be used in the future to investigate this relationship.

Small sample sizes are a common problem when studying elite populations; the sample of 20 elite fast bowlers used in the current study represents a relatively large sample for this particular population. Although the sample size limits the power of the statistical tests that can be conducted, there is sufficient data to enable correlations to be used. The issue of whether to use a single trial that represents the performance of each bowler or average a number of trials by the same performer is yet to be fully resolved. Some cricket studies have used one trial person to quantify the technique used by an individual (Portus et al., 2004; Glazier et al., 2000), others have used three trials per person (Ranson et al., 2008) and the International Cricket Council require six deliveries for the analysis of bowling legality. In this study, three trials per bowler were averaged to give representative data for each bowler with analysis of variance used as a justification. Further research is warranted to determine the optimal number of trials required to estimate the mean values for different kinetic and kinematic variables.

This study suggests the key determinant of ball release speed in fast bowling is the horizontal impulse generated at the ground, between front foot contact and ball release, not peak forces and loading rates as has been suggested previously. These findings indicate that there does not necessarily need to be a trade-off between maximum ball release speed and the forces exerted on the body (peak ground reaction forces and average loading rates). Consequently this study implies that bowling faster does not necessarily increase the ground reaction force loading experienced by the bowler, and from that perspective, bowling faster may not necessarily result in increased risk of injury. To understand the mechanics of these relationships in more detail including the link between linear and angular momentum, future studies could use simulation modelling to investigate the generation of ball speed by fast bowlers. Furthermore, this study implies that fast bowling coaches should incorporate a measurement of plant angle within talent identification and potentially develop practices that encourage appropriate plant angles (around 36 ; Table 2) at front foot contact.

\section{ACKNOWLEDGEMENTS}

This project was funded by the England and Wales Cricket Board (ECB).

\section{REFERENCES}

Bartlett, R.M., Stockill, N.P., Elliott, B.C., Burnett, A.F. 1996. The biomechanics of fast bowling in men's cricket: A review. Journal of Sports Sciences, 14, 403-424.

Burden, A.M., Bartlett, R.M. 1990. A kinematic investigation of elite fast and fast medium cricket bowlers. In Proceedings of the VIIIth International Symposium of the Society of Biomechanics in Sports (Eds M. Nosek, D. Sojka, W.E. Morrison and P. Susanka), pp. 41-46. Conex: Prague.

Burnett, A., O'Sullivan, P., Ankarberg, L., Gooding, M., Nelis, R., Offermann, F., Persson, J. 2008. Lower lumbar spine axial rotation is reduced in end-range sagittal postures when compared to a neutral spine posture. Manual Therapy, 13, 300-306. 
Chumanov, E. S., Heiderscheit, B. C., Thelen, D. G. 2011. Hamstring musculotendon dynamics during stance and swing phases of high-speed running. Medicine and Science in Sports and Exercise, 43, 525-532.

Davis, K., Blanksby, B. 1976. A cinematographical analysis of fast bowling in cricket. Australian Journal for Health, Physical Education and Recreation, 71, 9-15.

Davis, R.B., Ounpuu, S., Tyburski, D., Gage, J.R. 1991. A gait analysis data collection and reduction technique. Human Movement Science, 10, 575-587.

Elliott, B.C., Foster, D., Gray, S. 1986. Biomechanics and physical factors affecting fast bowling. Australian Journal of Science and Medicine in Sport, 18, 16-21.

Glazier, P.S., Paradisis, G.P., Cooper, S.M. 2000. Anthropometric and kinematic influences on release speed in men's fast-medium bowling. Journal of Sports Sciences, 18, 1013-1021.

Gregory, P.L., Batt, M.E., Kerslake, R.W. 2004. Comparing spondylolysis in cricketers and soccer players. British Journal of Sports Medicine, 38, 737-742.

Hurrion, P.D., Dyson, R., Hale, T. 2000. Simultaneous measurement of back and front foot ground reaction forces during the same delivery stride of the fastmedium bowler. Journal of Sports Sciences, 18, 993-997.

Norton, K., Marfell-Jones, M., Whittingham, N., Kerr, D., Carter, L., Saddington, K., Gore, C. 2000. Anthropometric assessment protocols. In C. Gore (Ed.), Physiological Tests for Elite Athletes. Lower Mitcham, South Australia: Human Kinetics.

Orchard, J.W., James, T., Portus, M.R. 2006. Injuries to elite male cricketers in Australia over a 10-year period. Journal of Science and Medicine in Sport, 9, 459467.

Orchard, J.W., James, T., Kountouris, A., Portus, M. 2010. Changes to injury profile and recommended cricket injury definitions based on the increased frequency of Twenty20 cricket matches. Open Access Journal of Sports Medicine, 1, 63-76.

Orchard, J.W. 2012. Hamstrings are most susceptible to injury during the early stance phase of sprinting. British Journal of Sports Medicine, 46, 88-89.

Portus, M.R., Mason, B.R., Elliott, B.C., Pfitzner, M.C., Done, R.P. 2004. Technique factors related to ball release speed and trunk injuries in high performance cricket fast bowlers. Sports Biomechanics, 3, 263-283.

Ranson, C.A., Kerslake, R.W., Burnett, A.F., Batt, M.E., Abdi, S. 2005. Magnetic resonance imaging of the lumbar spine in asymptomatic professional fast bowlers in cricket. The Journal of Bone and Joint Surgery, 87-B, 1111-1116.

Ranson, C.A., Burnett, A.F., King, M., Patel, N., O'Sullivan, P.B. 2008. The relationship between bowling action classification and three-dimensional lower trunk motion in fast bowlers in cricket. Journal of Sports Sciences, 26, 267-276.

Ranson, C.A., Burnett, A.F., Kerslake, R.W. 2010. Injuries to the lower back in elite fast bowlers: acute stress changes on MRI predict stress fracture. The Journal of Bone and Joint Surgery, 92, 1664-1668.

Winter, D.A. 1990. Biomechanics and Motor Control of Human Movement. New York: Wiley.

Weyand, P.G., Sternlight, D.B., Bellizzi, M.J., Wright, S. 2000. Faster top running speeds are achieved with greater ground forces not more rapid leg movements. Journal of Applied Physiology, 89, 1991-1999. 
Wormgoor, S., Harden, L., Mckinon, W. 2010. Anthropometric, biomechanical, and isokinetic strength predictors of ball release speed in high-performance cricket fast bowlers. Journal of Sports Sciences, 28, 957-965.

Worthington, P.W., King, M.A., Ranson, C. 2013a. Relationships between fast bowling technique and ball release speed in cricket. Journal of Applied Biomechanics, 29, 78-84.

Worthington, P.W., King, M.A., Ranson, C. 2013b. The influence of cricket fast bowlers' front leg technique on peak ground reaction forces. Journal of Sports Sciences, 31, 434-441.

Yeadon, M.R. 1990. The simulation of aerial movement - II: A mathematical inertia model of the human body. Journal of Biomechanics, 23, 67-74. 